\title{
EDITORIAL
}

\section{Notes from the editorial team}

\section{Henrik Åström Elmersjö (on behalf of the editorial team)}

$\mathrm{T}$ The eighth volume of the Nordic Journal of Educational History consists of this open issue and a special issue on educational finance published in cooperation with the French journal Histoire de l'éducation. This cooperation means that the NJEdH will publish the articles of the special issue in English and Histoire de l'éducation will publish the same articles in French. The aim of this kind of cooperation is to establish both the importance of smaller international journals-not exclusively publishing in English - in our field as well as to increase the reach of research published in the two journals. We also believe this way of disseminating the same research to different parts of the research community will strengthen international cooperation and help create constructive cohesion in the research field.

On the same note of constructive cohesion and international cooperation, the NJEdH is proud to once again be a part of organising the Nordic Educational History Conference, to be held in Aalborg, 25-27 May 2022. This will be the eighth conference, with the inaugural conference having been held in Stockholm in 1998. The theme for the conference in Aalborg is "Global and Local Histories of Education and the States," which connects very well with the research environments at Aalborg University, including the Centre for Education Policy Research, the Centre for History (The research groups for Knowledge, Sustainability and Heritage (KSH)) and Conflict, Coercion, and Authority in History (CCA). For the third time, the conference will also produce a special issue for the $\mathrm{NJEdH}$, with educational historians from Aalborg University as guest editors. This special issue will be published in late 2023 or early 2024. We hope we will see you all (in person) in Aalborg!

The breadth of Nordic educational history is once again evident in this year's open issue, shown both in the published articles and in the review section. While all three articles deal with the twentieth century, they also present vastly different topics within educational history.

In the first article, David Thorsén investigates attempts in the early twentieth century to introduce dissections of small animals in Swedish schools, particularly in primary and secondary girls' schools. By focusing on one of the stronger voices for this kind of teaching, namely Sweden's first female licensed physician Karolina Widerström, Thorsén gives a concrete example of the ambitions of the wider reform movement working for the modernisation of natural science teaching. 
The second article, written by Lina Rahm, deals with non-formal adult education in the second half of the twentieth century within the labour movement in response to the problematisations of digital technology. Rahm shows how problematisations of "the digital" have changed over time and how these problematisations exist on a spectrum from techno-utopian visions to techno-dystopian predictions, as well as how these two extremes call for different kinds of education aimed at either adapting humans or adapting machines.

In the third article, Carl-Filip Smedberg studies conceptualisations of social class in Swedish educational research, particularly focusing on the concept of a "pool of talent" launched by politicians in the 1940s in order to describe the societal wastefulness of only providing higher education to the elite. This leads Smedberg to the investigation of debates regarding categorisation of social groups as a way of describing the Swedish societal structure because this is what the idea of a "pool of talent" was based on. The author shows that the social group taxonomy that was utilised was becoming a standard tool in educational research at the same time as it was being criticised for being unscientific.

We hope you will enjoy this issue, which also contains a number of very interesting book reviews. And once again, we hope to see you in Aalborg in May 2022. 